\title{
Current advances of long non-coding RNA highly upregulated in liver cancer in human tumors
}

This article was published in the following Dove Press journal:

OncoTargets and Therapy

25 September 2017

Number of times this article has been viewed

\author{
Zhonghua $\mathrm{Ma}^{1,2, *}$ \\ Hesuyuan Huang $g^{3, *}$ \\ Yetao $\mathrm{Xu}^{4}$ \\ Xuezhi $\mathrm{He}^{5}$ \\ Jirong Wang ${ }^{2}$ \\ Bingqing Hui ${ }^{1,2}$ \\ Hao Ji ${ }^{1,2}$ \\ Jing Zhou ${ }^{1,2}$ \\ Keming Wang ${ }^{1,2}$ \\ 'The Second Clinical Medical College, \\ 2Department of Oncology, Second \\ Affiliated Hospital, ${ }^{3}$ Department \\ of Cardiothoracic Surgery, \\ Children's Hospital, ${ }^{4}$ Department \\ of Obstetrics and Gynecology, First \\ Affiliated Hospital, ${ }^{5}$ Department of \\ Biochemistry and Molecular Biology, \\ Nanjing Medical University, Nanjing, \\ Jiangsu, People's Republic of China \\ *These authors contributed equally \\ to this work
}

\begin{abstract}
Long non-coding RNAs (lncRNAs) are a group of non-coding RNAs (ncRNAs) > 200 nucleotides in length that govern diverse biological processes. Recent evidence suggests that lncRNAs are involved in cancer cell proliferation, apoptosis, invasion, migration, and metastasis. Dysregulation of lncRNAs has been observed in various tumors, and lncRNAs act as oncogenes or tumor suppressors in these malignancies. It has been revealed that lncRNA highly upregulated in liver cancer (HULC) is tightly correlated with a number of cancers such as hepatocellular carcinoma, gastric cancer, colorectal cancer, osteosarcoma, and diffuse large B-cell lymphoma. Depletion of HULC suppressed cancer cell proliferation, migration, and invasion and induced apoptosis. Additionally, HULC may function as a diagnostic biomarker and prognostic indicator for some tumors. In this review, we summarize the current knowledge of the role of HULC in cancer progression and the clinical management of human cancers.
\end{abstract}

Keywords: IncRNA, HULC, cancer

\section{Introduction}

Long non-coding RNAs (lncRNAs) are transcripts of $>200$ nucleotides in length without protein-coding ability that have recently been found to be pervasively transcribed in the human genome. ${ }^{1}$ Increasing numbers of studies have shown that lncRNAs exert important roles in cancer development and progression. The molecular functions executed by lncRNAs have been summarized as signals, decoys, guides, and scaffolds. ${ }^{2}$ It has been elucidated that lncRNAs are involved in various biological processes including gene expression, RNA splicing, and ligand-receptor engagement, mediating the pathogenesis of numerous human diseases ${ }^{3-5}$ Furthermore, recent investigations have demonstrated that lncRNAs are aberrantly expressed in many malignancies such as liver cancer, colorectal cancer (CRC), gastric cancer (GC), lung cancer, and breast cancer. Thus, lncRNAs play oncogenic and anti-tumor roles in tumor progression, and the levels of certain lncRNAs could be used as diagnostic markers and prognostic indicators. ${ }^{6-8}$

Highly upregulated in liver cancer (HULC) has been identified to closely associate with a number of tumors, including human hepatocellular carcinoma (HCC), ${ }^{9}$ GC, ${ }^{10}$ CRC, ${ }^{11}$ osteosarcoma (OS), ${ }^{12}$ and B-cell lymphoma. ${ }^{13}$ Inhibition of HULC suppresses cancer cell proliferation and promotes apoptosis in some tumors. Emerging evidence suggests that HULC may act as a biomarker for tumor diagnosis and prognosis monitoring. In this review, we summarize the current knowledge of the role of HULC in the cancer progression and the clinical management of human cancers (Table 1).
Correspondence: Keming Wang Department of Oncology, Second Affiliated Hospital, Nanjing Medical University, 262 Zhongshan Road, Nanjing, Jiangsu, People's Republic of China

Tel +86 I895I76 2692

Fax +8625 58509994

Email kemingwang@njmu.edu.cn
OncoTargets and Therapy 2017:10 47। I-47। 7

47 I

Dovepress f $y$ in $\mathbf{0}$

http://dx.doi.org// $0.2147 / 0 T T . S 136915$ (c) (1) (2) $2017 \mathrm{Ma}$ et al. This work is published and licensed by Dove Medical Press Limited. The full terms of this license are available at https://www.dovepress.com/terms.php
and incorporate the Creative Commons Attribution - Non Commercial (unported, v3.0) License (http:///creativecommons.org/licenses/by-nc/3.0/). By accessing the work you BY NC and incorporate the Creative Commons Attribution - Non Commercial (unported, v3.0) License (http://creativecommons.org/licenses/by-nc/3.0/). By accessing the work you
hereby accept the Terms. Non-commercial uses of the work are permitted without any further permission from Dove Medical Press Limited, provided the work is properly attributed. For permission for commercial use of this work, please see paragraphs 4.2 and 5 of our Terms (https://www.dovepress.com/terms.php). 
Table I Functions and applications of upregulated HULC in various tumors

\begin{tabular}{|c|c|c|c|c|}
\hline Tumor types & Expression & Functions & Applications & References \\
\hline $\mathrm{HCC}$ & Up & $\begin{array}{l}\text { Proliferation, apoptosis, invasion, } \\
\text { metastasis, tumorigenesis }\end{array}$ & $\begin{array}{l}\text { Staging biomarker, diagnostic biomarker, } \\
\text { prognostic indicator, therapeutic target }\end{array}$ & $|4,26,27,3|-33$ \\
\hline GC & Up & $\begin{array}{l}\text { Proliferation, apoptosis, } \\
\text { suppression, invasion, } \\
\text { metastasis, EMT }\end{array}$ & $\begin{array}{l}\text { Staging biomarker, diagnostic biomarker, } \\
\text { prognostic indicator, therapeutic target }\end{array}$ & 10,37 \\
\hline CRC & Up & $\begin{array}{l}\text { Proliferation, apoptosis, migration, } \\
\text { invasion, metastasis, tumorigenesis }\end{array}$ & $\begin{array}{l}\text { Diagnostic biomarker, prognostic } \\
\text { indicator, therapeutic target }\end{array}$ & 11,43 \\
\hline PC & Up & Proliferation, invasion, metastasis & $\begin{array}{l}\text { Staging biomarker, diagnostic biomarker, } \\
\text { prognostic indicator, therapeutic target }\end{array}$ & 48 \\
\hline OS & Up & $\begin{array}{l}\text { Proliferation, migration, invasion, } \\
\text { metastasis }\end{array}$ & $\begin{array}{l}\text { Staging biomarker, diagnostic biomarker, } \\
\text { prognostic indicator, therapeutic target }\end{array}$ & 12,54 \\
\hline DLBCL & Up & $\begin{array}{l}\text { Proliferation, apoptosis, } \\
\text { suppression }\end{array}$ & $\begin{array}{l}\text { Diagnostic biomarker, prognostic } \\
\text { indicator, therapeutic target }\end{array}$ & 13 \\
\hline Glioma & Up & $\begin{array}{l}\text { Proliferation, adhesion, migration, } \\
\text { invasion, angiogenesis }\end{array}$ & $\begin{array}{l}\text { Diagnostic biomarker, prognostic } \\
\text { indicator, therapeutic target }\end{array}$ & 13,57 \\
\hline
\end{tabular}

Abbreviations: HULC, highly upregulated in liver cancer; HCC, hepatocellular carcinoma; GC, gastric cancer; EMT, epithelial-mesenchymal transition; CRC, colorectal cancer; PC, pancreatic cancer; OS, osteosarcoma; DLBCL, diffuse large B-cell lymphoma.

\section{Characterization of HULC}

HULC, located on chromosome 6p24.3 (data from UCSC website; http://genome-asia.ucsc.edu/cgi-bin/hgTracks $\underline{? \mathrm{db}}=\mathrm{hg} 38 \&$ lastVirtModeType $=$ default $\&$ lastVirtMode ExtraState $=\&$ virtModeType $=$ default $\&$ virtMode $=0 \& n$ onVirtPosition=\&position $=$ chr6\%3A8652209\%2D 865 3846\&hgsid=471875206 bqLwOkwNkIK5wmKztR6yq 3iR2yzq), was first recognized as a novel messenger RNA (mRNA)-like lncRNA with two exons and dramatically increased expression in human HCC, using an HCC-specific complementary DNA (cDNA) microarray platform. ${ }^{9}$ The full sequence of HULC can be obtained from the Entrez Gene database (https://www.ncbi.nlm.nih.gov/nuccore/ NR 004855.2). Additionally, the prediction of HULC structure based on MFE and partition function can be obtained from ViennaRNA website (http://rna.tbi.univie.ac.at//cgi-bin/ RNAWebSuite/RNAfold.cgi?PAGE=3\&ID=0J41idlxsN). It has been widely reported that $\sim 20 \%$ of all lncRNAs can bind to polycomb repressive complex 2 (PRC2), which consists of enhancer of zeste homolog 2 (EZH2), suppressor of zeste 12 (SUZ12), and embryonic ectoderm development (EED) proteins and mediates methyltransferase activities. ${ }^{14-16} \mathrm{HULC}$ interaction with $\mathrm{PRC} 2$, which functions as a transcriptional silencer, could mediate CRC progression. ${ }^{11}$

Function investigations found that depletion of HULC leads to genomic and morphological alterations in poorly differentiated SK-Hep-1 cells, implying its crucial roles in mesenchymal phenotype maintenance. ${ }^{17}$ Furthermore, transfection of HCC cells with si-HULC significantly decreased cell proliferation, migration, and invasion and facilitated cell apoptosis. ${ }^{17} \mathrm{HULC}$, identified as a microRNA
(miRNA) sponge, can decrease the expression of a number of miRNAs. ${ }^{18}$ Knockdown of HULC could impair translational repression of its target gene, which results in alterations in the patterns of the deacetylation and methylation of histones. ${ }^{19}$ Furthermore, RNA immunoprecipitation (RIP) and RNA pull-down assays indicated that HULC can inhibit miR-9 expression through association with DNA methyltransferase mediating TNF- $\alpha$-induced apoptosis. ${ }^{20}$ Thus, the HULCmiR-9 pathway may be a potential target for atherosclerosis treatment. Recently, it has been recognized that patients with HCC with high HULC expression levels could benefit from metformin treatment, and the serum level of HULC may be a biomarker of treatment efficacy. ${ }^{17}$

\section{Potential clinical implications of HULC $\mathrm{HCC}$}

$\mathrm{HCC}$ is the third leading cause of cancer-related death annually and the sixth most common malignancy worldwide..$^{21,22}$ In China, HCC is one of the four leading causes of cancerrelated death ${ }^{23}$ and this dismal prognosis is associated with frequent cancer metastasis, tumor recurrence, and a lack of curative treatment. ${ }^{24}$ Large-scale studies have been undertaken to investigate the comprehensive treatment options for HCC treatment, including surgical resection, chemotherapy, orthotopic liver transplantation (OLT), transcatheter arterial chemoembolization (TACE), and targeted immunotherapy, ${ }^{25,26}$ and most of these therapies are only available at an early stage. ${ }^{24}$ However, the patients are frequently diagnosed at an intermediate or advanced stage due to the lack of novel diagnostic biomarkers. ${ }^{27}$ Therefore, 
identifications of effective novel molecular biomarkers and therapeutic targets in $\mathrm{HCC}$ are critical and will help to accelerate the research on HCC pathogenesis.

Panzitt et $a{ }^{18}$ first demonstrated that lncRNA HULC was specifically expressed in hepatocytes and highly upregulated in $\mathrm{HCC}$ specimens (including $46 \mathrm{HCCs}$, four focal nodular hyperplasia [FNH], seven cirrhosis, and two non-neoplastic liver samples). Quantitative polymerase chain reaction (qPCR) was performed to investigate the lncRNA HULC expression at the mRNA levels and showed that HULC exhibited on average 33-fold (32.7 \pm 5.0 , $P=0.16)$ upregulation over the non-neoplastic liver pool in $76 \%(35 / 46)$ of HCCs. In addition, the aberrant expression of HULC in HCC tissues was related to tumornode-metastasis (TNM) stage, intrahepatic metastases, HCC recurrence, and postoperative survival. ${ }^{9}$ Recently, a preliminary analysis of the Gene Expression Omnibus (GEO) revealed that HULC was significantly associated with overall survival in patients with $\mathrm{HCC}(P=0.005){ }^{28}$ Interestingly, Yang et $\mathrm{al}^{28}$ verified that HULC had a significant association with vascular invasion, which should be a positive factor for HCC prognosis, and univariate and multivariate Cox regression analyses also confirmed that upregulation of HULC in tumor tissues contributed to better outcomes both for overall survival and in diseasefree survival.

The detection of lncRNA HULC in blood from patients with HCC implies its potential use as a novel biomarker. ${ }^{9}$ Li et $\mathrm{al}^{29}$ demonstrated that IncRNA HULC and Linc00152 expression levels in plasma samples from patients with HCC were significantly upregulated and correlated with tumor growth and metastasis of HCC. Thus, HULC and Linc00152 may function as potential diagnostic biomarkers and therapeutic targets for patients with HCC. ${ }^{29}$ Furthermore, HULC dysregulation can alter the expression of HCCrelated genes to regulate gene expression. Du et a ${ }^{30}$ reported that $\mathrm{HBx}$-induced upregulation of HULC could promote HCC proliferation by silencing cyclin-dependent kinase inhibitor 2C (CDKN2C, P18) at the mRNA and protein levels. Moreover, Wan et a ${ }^{31}$ illustrated that the expression of HULC and tumor suppressor miR-203 in HCC tissues or cell lines was inversely correlated and miR-203-induced HULC impairment dramatically diminished HCC cell proliferation and invasion and mediated cell apoptosis. Additionally, the abnormal activity of HULC could regulate human liver stem cell differentiation and tumor angiogenesis through miR-107/ transcription factor E2F1/sphingosine kinase 1 (SPHK1) signaling to promote tumorigenesis in human HCC..$^{11,32,33}$
A functional and mechanistic study revealed that HULC could serve as a competing endogenous RNA (ceRNA) to sponge with miR-200a-3p and exerteffects in HCC progression through zinc finger E-box-binding homeobox 1 (ZEB1)induced epithelial-mesenchymal transition (EMT). Accordingly, Panzitt et a ${ }^{18}$ discovered that downregulation of HULC can inhibit growth and metastasis in vitro and in vivo. The variant genotypes of rs7763881 in HULC discovered by Liu et $\mathrm{al}^{34}$ have been investigated for their association with decreased HCC susceptibility in hepatitis B virus persistent carriers; a full investigation of the molecular mechanisms of HULC in the natural progression of hepatitis B virus infection to HCC development should be performed. Recently, Cui et a ${ }^{35}$ concluded that retinoid $\mathrm{X}$ receptor alpha (RXRA) can activate the HULC promoter, and the corresponding feedback loop can upregulate the expression of HULC to facilitate malignant development via abnormal lipid metabolism in hepatoma cells through an miR-9-mediated RXRA signaling pathway. In addition, lncRNA HULC can also be induced by the transcription factor cAMP response element binding (CREB) protein through sequestration of miRNA-372. ${ }^{19}$ The protumorigenic mechanisms of HULC in HCC are involved with different regulatory pathways (Figure 1A). These findings implied that HULC may be a crucial factor in HCC initiation and progression and confirm that lncRNA HULC could act as a novel prognostic marker and potential therapeutic target for HCC. However, larger samples and further mechanistic investigations are urgently needed to support these findings.

\section{GC}

GC is currently one of the leading causes of cancer-related death, especially in Asia, ${ }^{36}$ and it has been defined as the second leading cause of cancer death in China with 679,000 newly reported cases and 498,000 GC-related deaths in 2015. ${ }^{23}$ Owing to a lack of an effective molecule biomarker, most patients with $\mathrm{GC}$ are often at an advanced stage when diagnosed and the prognosis is poor even with surgery, chemotherapy, and radiotherapy due to relapse risk, distant metastasis, and chemoresistance. ${ }^{37}$ Thus, a better understanding of the molecular mechanisms underlying the development of GC may help identify sensitive diagnostic and prognostic biomarkers and therapeutic targets.

Jin et $\mathrm{al}^{10}$ investigated the serum HULC level of patients with GC using quantitative real-time polymerase chain reaction (qRT-PCR) and found high expression of circulating HULC in GC patients, implying its novel functions 


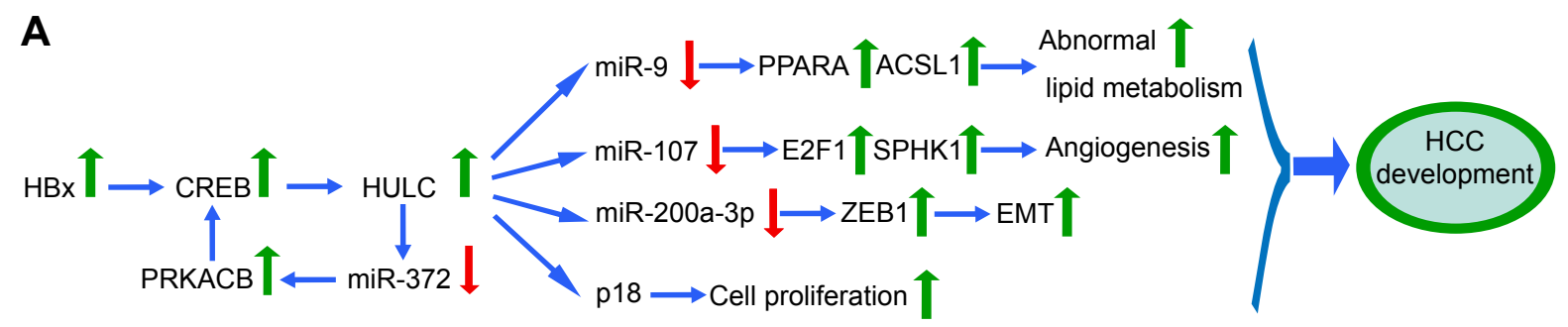

B Location: $6 \mathrm{p} 24.3$
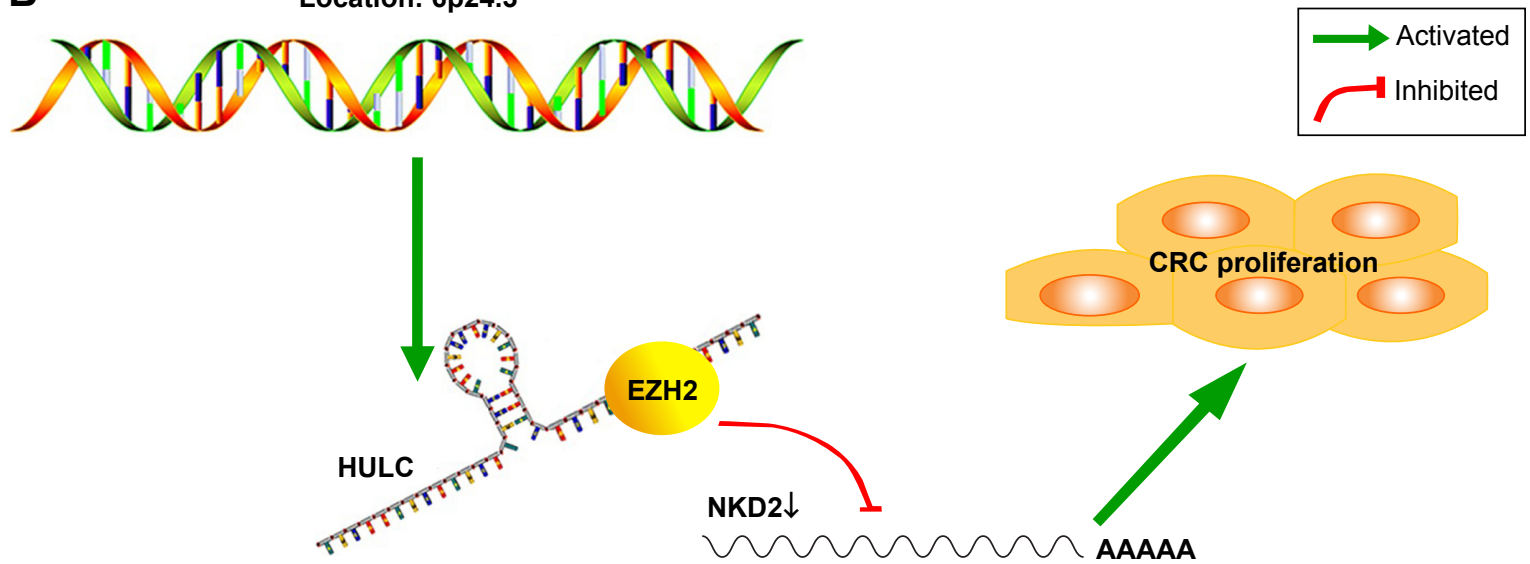

Figure I The protumorigenic mechanisms of HULC overexpression in HCC and CRC.

Notes: (A) HULC could promote cancer development through regulatory pathways in HCC. (B) Summary diagram describes that HULC regulates CRC cell proliferation. Abbreviations: HULC, highly upregulated in liver cancer; HCC, hepatocellular carcinoma; CRC, colorectal cancer; CREB, CAMP response element binding; SPHKI, sphingosine kinase I; ZEBI, zinc finger E-box-binding homeobox I; EMT, epithelial-mesenchymal transition; EZH2, enhancer of zeste homolog 2.

as a serum tumor marker for diagnosis and a monitoring indicator for prognosis. Moreover, they also showed that HULC overexpression in serum was associated with tumor size, lymph node metastasis, distant metastasis, TNM stage, and Helicobacter pylori infection. Another study elucidated significant HULC overexpression in GC cell lines and GC tissues compared with normal controls, and functional analyses revealed that depletion of HULC inhibited cell proliferation and invasion, induced apoptosis, and reversed EMT in GC. ${ }^{38}$ Furthermore, elevated expression of HULC could mediate cancer cell proliferation and invasion and suppress apoptosis by activating autophagy. ${ }^{38}$

In conclusion, silencing HULC expression could inhibit GC cell proliferation. Moreover, lncRNA HULC might serve as an oncogene in GC progression, suggesting its utilities as a candidate diagnostic biomarker and a novel therapeutic target. However, massive efforts are needed to explore the underlying regulatory mechanism.

\section{CRC}

$\mathrm{CRC}$ is the third most common malignancy worldwide with 1,200,000 newly diagnosed cases annually ${ }^{39,40}$ and is characterized by a poor prognosis with $\sim 600,000$ deaths each year. ${ }^{41}$ The diagnostic biomarkers frequently used in the clinic at present have been shown to lack sensitivity and specificity, which leads to difficulties of early diagnosis and challenges for CRC therapy. ${ }^{42,43}$ Therefore, identifications of novel diagnostic and therapeutic biomarkers would be of great clinical significance.

Matouk et $\mathrm{al}^{44}$ reported that HULC was expressed neither in primary CRC samples nor in their normal counterparts. Moreover, upregulation of HULC was found in patients with $\mathrm{CRC}$ who had distant metastasis of liver cancer, highlighting its specificity to malignant cells located in the liver. ${ }^{44}$ However, the earlier investigation has been reported and updated in recent years. Yang et $\mathrm{al}^{11}$ demonstrated that HULC was upregulated in CRC tissues and cells and associated with poor prognosis and shorter survival for CRC patients. Moreover, depletion of HULC suppressed tumorigenicity of CRC cells in vivo and impaired CRC cells proliferation, migration, and invasion and induced cell apoptosis in vitro. ${ }^{11}$ Importantly, the oncogenic function mediated by HULC is partially induced by epigenetically silencing NKD2 expression via direct interaction with EZH2 (a part of PRC2) (Figure 1B). ${ }^{11}$ These observations implied that HULC would be a crucial biomarker and useful therapeutic target in CRC. 


\section{Pancreatic cancer (PC)}

$\mathrm{PC}$ is a malignant neoplasm ${ }^{45}$ and ranks as the fourth leading cause of cancer-related death in Western society. ${ }^{39}$ Although comprehensive treatments for PC have been rapidly developed recently, the therapeutic efficacy of PC is still far from satisfactory as the early detection and diagnosis of $\mathrm{PC}$ are difficult. ${ }^{46,47}$ Therefore, the major drawback with PC is late diagnosis.

The expressions of HULC in 304 patients with PC were investigated by qRT-PCR, and the findings showed that HULC expression in tumor tissues was significantly higher than that in adjacent normal tissues. ${ }^{48}$ Moreover, they also showed that higher expression of HULC was significantly correlated with larger tumor size, advanced lymph node metastasis, and vascular invasion. Further studies revealed that reducing HULC expression significantly impaired PC cell proliferation by blocking the G1/S-phase transition in vitro. ${ }^{48}$

Taucher et $\mathrm{a}^{49}$ reported that HULC expression levels could help to distinguish cancer tissues from healthy tissues, and the certain HULC levels had a significant relationship with dismal overall survival and recurrence of PC in patients. Additionally, multivariate analyses confirmed that HULC could be an independent predictor for overall sur$\operatorname{vival}(P=0.032),{ }^{48}$ and Kaplan-Meier analysis demonstrated significant differences between patients with high and low HULC expression. Thus, HULC may serve as a highly sensitive screening biomarker and a potential therapeutic target in patients with PC. ${ }^{48}$

\section{OS}

OS, the most common malignant bone tumor that often presents with structural chromosomal alterations, occurs predominantly in adolescents and young adults and accounts for $5 \%$ of childhood cancers. ${ }^{50,51}$ Despite advances in clinical treatments involving surgical resection combined with chemotherapy and/or radiotherapy, ${ }^{52,53}$ the invasive nature of the disease continues to limit the 5 -year survival with OS to merely $20 \%$. Therefore, new, non-conventional treatments using therapeutic targets may help to improve clinical efficacy.

Sun et $\mathrm{l}^{54}$ showed that HULC was significantly upregulated in OS tissues and cell lines compared with normal controls. And the tumors in patients with dramatically expressed HULC often show more aggressive behavior and/or metastatic potential. ${ }^{54}$ Sun et $a l^{54}$ revealed that the proliferation, migration, and invasion capacity impairment in OS cell lines resulted in part from inhibition of HULC using small interfering RNA (siRNA). Moreover, they also reported that HULC level was correlated with clinical stage, distant metastasis, prognosis, and survival rates in patients with OS, in terms of both overall and event-free survival. ${ }^{54}$ To further study the relationship between HULC expression and clinicopathological characteristics of patients with OS, a larger sample size is needed. ${ }^{12}$

It has been verified that HULC could be a potential prognostic biomarker in OS. ${ }^{12}$ Sun et a ${ }^{54}$ further confirmed that HULC may be implicated in early prognosis and could act as a therapeutic target in patients with OS. These results highlight the critical and novel role of HULC in OS.

\section{Other human cancers}

Diffuse large B-cell lymphoma (DLBCL) is the most common subtype of lymphoma. ${ }^{55}$ Peng et a ${ }^{13}$ demonstrated that HULC was remarkably overexpressed in both DLBCL tissues and cell lines, and HULC expression was closely associated with DLBCL characteristics, such as Ann Arbor stages, B symptoms, CHOP-like (cyclophosphamide, doxorubicin, vincristine, and prednisone) treatment, rituximab treatment, and international prognostic index (IPI). Furthermore, a large number of samples from the long-term follow-ups indicated that HULC can be considered as an independent diagnostic and prognostic marker in patients with DLBCL. ${ }^{13}$ Additionally, HULC depletion could significantly inhibit cell proliferation and promote apoptosis by repressing cyclin D1 and Bcl-2 in DLBCL cells, and targeting HULC may be a potential gene therapy for patients with DLBCL. ${ }^{13}$

Glioma accounts for $\sim 80 \%$ of primary malignant brain tumors and exhibits exceptionally high morbidity and mortality. ${ }^{56}$ It has been documented that HULC, vascular endothelial growth factor (VEGF), and endothelial cell-specific molecule 1 (ESM-1) expression, as well as microvessel density, are positively correlated with grade dependency in tissues from glioma patients. They further discovered that HULC could act as an oncogene in gliomas, and its depletion impairs glioma cell proliferation, adhesion, migration, invasion, and angiogenesis induced by ESM-1 through cell cycle alteration, which leads to angiogenesis suppression. ${ }^{57}$ Moreover, ESM-1 involvement of the phosphatidylinositol 3 kinase/protein kinase $\mathrm{B} /$ mechanistic target of rapamycin signaling pathway can induce anoikis and blocked the cell cycle progression at $\mathrm{G} 1 / \mathrm{S}$ phase in glioma, altering the expressions of tumor-related genes. ${ }^{57}$ These findings implied that HULC could promote pro-angiogenesis activity and serve as a potential therapeutic target in glioma treatment. ${ }^{57}$

In summary, aberrant expression of HULC plays important roles in the progression of DLBCL and glioma, and there is an urgent need to develop novel therapeutic modalities that 
specifically and sensitively target the pathogenesis of these lethal malignancies.

\section{Concluding remarks and future perspectives}

Dysregulation of lncRNAs is correlated with various cancers. Diagnostic biomarkers and therapeutic targets are essential for early diagnosis and treatment. The rapid development of next-generation sequencing and high-resolution microarray techniques can help to identify the expression and role of lncRNAs in malignancies. HULC involvement has been identified in many cancers, mediating cancer cell proliferation, apoptosis, invasion, and metastasis. Importantly, HULC possesses tremendous diagnostic and therapeutic potential in many cancers.

Although HULC has been characterized, the underlying mechanisms contributing to cancer progression remain unclear. Further investigations of HULC can bring novel insights into the diagnosis and treatment of cancer, and more efforts should be devoted to the development of HULCbased treatment. However, its clinical implications in cancer prevention and treatment still have a long way to go.

\section{Acknowledgments}

This work was supported by the Medical Science and Technology Development Foundation, Jiangsu Province Department of Health (H201407), the Six Talents Peak Project of Jiangsu Province (WSN-050), the Natural Science Foundation of Jiangsu Province of China (BK20151578), the Natural Science Fund Project of Jiangsu Province (15KJB320006), and the Medical Science and Technology Development Foundation of Nanjing (YKK13178).

\section{Author contributions}

Zhonghua Ma and Hesuyuan Huang contributed equally to this work. Yetao $\mathrm{Xu}$ and Xuezhi He contributed to drafting and editing of the manuscript. Jirong Wang and Bingqing Hui participated in the conception of the idea. Hao Ji and Jing Zhou contributed to literature search. Keming Wang participated in the conception and coordination. All authors contributed toward data analysis, drafting and revising the paper and agreed to be accountable for all aspects of the work.

\section{Disclosure}

The authors report no conflicts of interest in this work.

\section{References}

1. Jiang Y, Malouf GG, Zhang J, et al. Long non-coding RNA profiling links subgroup classification of endometrioid endometrial carcinomas with trithorax and polycomb complex aberrations. Oncotarget. 2015; 6(37):39865-39876.
2. Li X, Wu Z, Fu X, Han W. lncRNAs: insights into their function and mechanics in underlying disorders. Mutat Res Rev Mutat Res. 2014; 762:1-21.

3. He Y, Meng XM, Huang C, et al. Long noncoding RNAs: novel insights into hepatocellular carcinoma. Cancer Lett. 2014;344(1):20-27.

4. Wang KC, Chang HY. Molecular mechanisms of long noncoding RNAs. Mol Cell. 2011;43(6):904-914.

5. Tsai MC, Manor O, Wan Y, et al. Long noncoding RNA as modular scaffold of histone modification complexes. Science. 2010;329(5992): 689-693.

6. Wang F, Yuan JH, Wang SB, et al. Oncofetal long noncoding RNA PVT1 promotes proliferation and stem cell-like property of hepatocellular carcinoma cells by stabilizing NOP2. Hepatology. 2014;60(4): $1278-1290$.

7. Yang $\mathrm{F}$, Zhang L, Huo XS, et al. Long noncoding RNA high expression in hepatocellular carcinoma facilitates tumor growth through enhancer of zeste homolog 2 in humans. Hepatology. 2011;54(5):1679-1689.

8. Yuan SX, Yang F, Yang Y, et al. Long noncoding RNA associated with microvascular invasion in hepatocellular carcinoma promotes angiogenesis and serves as a predictor for hepatocellular carcinoma patients' poor recurrence-free survival after hepatectomy. Hepatology. 2012; 56(6):2231-2241.

9. Li SP, Xu HX, Yu Y, et al. LncRNA HULC enhances epithelialmesenchymal transition to promote tumorigenesis and metastasis of hepatocellular carcinoma via the miR-200a-3p/ZEB1 signaling pathway. Oncotarget. 2016;7(27):42431-42446.

10. Jin C, Shi W, Wang F, et al. Long non-coding RNA HULC as a novel serum biomarker for diagnosis and prognosis prediction of gastric cancer. Oncotarget. 2016;7(32):51763-51772.

11. Yang XJ, Huang CQ, Peng CW, Hou JX, Liu JY. Long noncoding RNA HULC promotes colorectal carcinoma progression through epigenetically repressing NKD2 expression. Gene. 2016;592(1):172-178.

12. Uzan VR, Lengert A, Boldrini E, et al. High expression of HULC is associated with poor prognosis in osteosarcoma patients. PLoS One. 2016;11(6):e156774.

13. Peng W, Wu J, Feng J. Long noncoding RNA HULC predicts poor clinical outcome and represents pro-oncogenic activity in diffuse large B-cell lymphoma. Biomed Pharmacother. 2016;79:188-193.

14. Sanulli S, Justin N, Teissandier A, et al. Jarid2 methylation via the PRC2 complex regulates $\mathrm{H} 3 \mathrm{~K} 27 \mathrm{me} 3$ deposition during cell differentiation. Mol Cell. 2015;57(5):769-783.

15. Liu C, Li S, Dai X, et al. PRC2 regulates RNA polymerase III transcribed non-translated RNA gene transcription through EZH2 and SUZ12 interaction with TFIIIC complex. Nucleic Acids Res. 2015; 43(13):6270-6284.

16. Xu B, Konze KD, Jin J, Wang GG. Targeting EZH2 and PRC2 dependence as novel anticancer therapy. Exp Hematol. 2015;43(8):698-712.

17. Gandhy SU, Imanirad P, Jin UH, et al. Specificity protein (Sp) transcription factors and metformin regulate expression of the long non-coding RNA HULC. Oncotarget. 2015;6(28):26359-26372.

18. Panzitt K, Tschernatsch MM, Guelly C, et al. Characterization of HULC, a novel gene with striking up-regulation in hepatocellular carcinoma, as noncoding RNA. Gastroenterology. 2007;132(1):330-342.

19. Wang J, Liu X, Wu H, et al. CREB up-regulates long non-coding RNA, HULC expression through interaction with microRNA-372 in liver cancer. Nucleic Acids Res. 2010;38(16):5366-5383.

20. Ma Y, Huang D, Yang F, et al. Long noncoding RNA highly upregulated in liver cancer regulates the tumor necrosis factor-alpha-induced apoptosis in human vascular endothelial cells. DNA Cell Biol. 2016;35(6):296-300.

21. Jemal A, Siegel R, Ward E, et al. Cancer statistics, 2008. CA Cancer J Clin. 2008;58(2):71-96.

22. Goh GB, Chang PE, Tan CK. Changing epidemiology of hepatocellular carcinoma in Asia. Best Pract Res Clin Gastroenterol. 2015;29(6): 919-928.

23. Chen W, Zheng R, Baade PD, et al. Cancer statistics in China, 2015. CA Cancer J Clin. 2016;66(2):115-132.

24. George J, Patel T. Noncoding RNA as therapeutic targets for hepatocellular carcinoma. Semin Liver Dis. 2015;35(1):63-74. 
25. Cervello M, McCubrey JA, Cusimano A, Lampiasi N, Azzolina A, Montalto G. Targeted therapy for hepatocellular carcinoma: novel agents on the horizon. Oncotarget. 2012;3(3):236-260.

26. Zhu Q, Li N, Zeng X, et al. Hepatocellular carcinoma in a large medical center of China over a 10-year period: evolving therapeutic option and improving survival. Oncotarget. 2015;6(6):4440-4450.

27. Maluccio M, Covey A. Recent progress in understanding, diagnosing, and treating hepatocellular carcinoma. CA Cancer J Clin. 2012;62(6): 394-399.

28. Yang Z, Lu Y, Xu Q, Tang B, Park CK, Chen X. HULC and H19 played different roles in overall and disease-free survival from hepatocellular carcinoma after curative hepatectomy: a preliminary analysis from gene expression omnibus. Dis Markers. 2015;2015:191029.

29. Li J, Wang X, Tang J, et al. HULC and Linc00152 act as novel biomarkers in predicting diagnosis of hepatocellular carcinoma. Cell Physiol Biochem. 2015;37(2):687-696.

30. Du Y, Kong G, You X, et al. Elevation of highly up-regulated in liver cancer (HULC) by hepatitis B virus X protein promotes hepatoma cell proliferation via down-regulating p18. J Biol Chem. 2012;287(31): 26302-26311.

31. Wan D, Shen S, Fu S, et al. miR-203 suppresses the proliferation and metastasis of hepatocellular carcinoma by targeting oncogene ADAM9 and oncogenic long non-coding RNA HULC. Anticancer Agents Med Chem. 2016;16(4):414-423.

32. Gui X, Li H, Li T, Pu H, Lu D. Long noncoding RNA CUDR regulates HULC and beta-catenin to govern human liver stem cell malignant differentiation. Mol Ther. 2015;23(12):1843-1853.

33. Wang R, Sun Q, Wang P, et al. Notch and Wnt/beta-catenin signaling pathway play important roles in activating liver cancer stem cells. Oncotarget. 2016;7(5):5754-5768.

34. Liu Y, Pan S, Liu L, et al. A genetic variant in long non-coding RNA HULC contributes to risk of HBV-related hepatocellular carcinoma in a Chinese population. PLoS One 2012;7(4):e35145.

35. Cui M, Xiao Z, Wang Y, et al. Long noncoding RNA HULC modulates abnormal lipid metabolism in hepatoma cells through an miR-9mediated RXRA signaling pathway. Cancer Res. 2015;75(5):846-857.

36. Tan P, Yeoh KG. Genetics and molecular pathogenesis of gastric adenocarcinoma. Gastroenterology. 2015;149(5):1153-1162.

37. Saka M, Morita S, Fukagawa T, Katai H. Present and future status of gastric cancer surgery. Jpn J Clin Oncol. 2011;41(3):307-313.

38. Zhao Y, Guo Q, Chen J, Hu J, Wang S, Sun Y. Role of long non-coding RNA HULC in cell proliferation, apoptosis and tumor metastasis of gastric cancer: a clinical and in vitro investigation. Oncol Rep. 2014;31(1) 358-364

39. Torre LA, Bray F, Siegel RL, Ferlay J, Lortet-Tieulent J, Jemal A. Global cancer statistics, 2012. CA Cancer J Clin. 2015;65(2):87-108.

40. Yu X, Li Z, Yu J, Chan MT, Wu WK. MicroRNAs predict and modulate responses to chemotherapy in colorectal cancer. Cell Prolif. 2015; 48(5):503-510.

41. Yang $\mathrm{MH}, \mathrm{Yu} \mathrm{J}$, Chen $\mathrm{N}$, et al. Elevated microRNA-31 expression regulates colorectal cancer progression by repressing its target gene SATB2. PLoS One. 2013;8(12):e85353
42. Wang RF, Song BR, Peng JJ, et al. The prognostic value of preoperative serum CEA and CA19-9 values in stage I-III colorectal cancer. Hepatogastroenterology. 2014;61(132):994-999.

43. Fung KY, Nice E, Priebe I, et al. Colorectal cancer biomarkers: to be or not to be? Cautionary tales from a road well travelled. World $J$ Gastroenterol. 2014;20(4):888-898.

44. Matouk IJ, Abbasi I, Hochberg A, Galun E, Dweik H, Akkawi M. Highly upregulated in liver cancer noncoding RNA is overexpressed in hepatic colorectal metastasis. Eur J Gastroenterol Hepatol. 2009;21(6): 688-692.

45. Malvezzi M, Bertuccio P, Levi F, La Vecchia C, Negri E. European cancer mortality predictions for the year 2014. Ann Oncol. 2014;25(8): 1650-1656.

46. Mayor S. Immunotherapy improves overall survival in pancreatic cancer. Lancet Oncol. 2015;16(2):e58.

47. Bergmann L, Maute L, Heil G, et al. A prospective randomised phase-II trial with gemcitabine versus gemcitabine plus sunitinib in advanced pancreatic cancer: a study of the CESAR Central European Society for Anticancer Drug Research-EWIV. Eur J Cancer. 2015;51(1): 27-36.

48. Peng W, Gao W, Feng J. Long noncoding RNA HULC is a novel biomarker of poor prognosis in patients with pancreatic cancer. Med Oncol. 2014;31(12):346.

49. Taucher V, Mangge H, Haybaeck J. Non-coding RNAs in pancreatic cancer: challenges and opportunities for clinical application. Cell Oncol (Dordr). 2016;39(4):295-318.

50. He H, Ni J, Huang J. Molecular mechanisms of chemoresistance in osteosarcoma (Review). Oncol Lett. 2014;7(5):1352-1362.

51. Liu JJ, Liu S, Wang JG, et al. Telangiectatic osteosarcoma: a review of literature. Onco Targets Ther. 2013;6:593-602.

52. Guo J, Reddick WE, Glass JO, et al. Dynamic contrast-enhanced magnetic resonance imaging as a prognostic factor in predicting event-free and overall survival in pediatric patients with osteosarcoma. Cancer. 2012;118(15):3776-3785.

53. Han G, Wang Y, Bi WZ, et al. Magnetic resonance imaging is appropriate for determining the osteotomy plane for appendicular osteosarcoma after neoadjuvant chemotherapy. Med Oncol. 2012;29(2):1347-1353.

54. Sun XH, Yang LB, Geng XL, Wang R, Zhang ZC. Increased expression of lncRNA HULC indicates a poor prognosis and promotes cell metastasis in osteosarcoma. Int J Clin Exp Pathol. 2015;8(3):2994-3000.

55. Iqbal J, Naushad $\mathrm{H}, \mathrm{Bi}$ C, et al. Genomic signatures in B-cell lymphoma: how can these improve precision in diagnosis and inform prognosis? Blood Rev. 2016;30(2):73-88.

56. Omuro A, DeAngelis LM. Glioblastoma and other malignant gliomas: a clinical review. JAMA. 2013;310(17):1842-1850.

57. Zhu Y, Zhang X, Qi L, et al. HULC long noncoding RNA silencing suppresses angiogenesis by regulating ESM-1 via the PI3K/Akt/ mTOR signaling pathway in human gliomas. Oncotarget. 2016;7(12) $14429-14440$
OncoTargets and Therapy

\section{Publish your work in this journal}

OncoTargets and Therapy is an international, peer-reviewed, open access journal focusing on the pathological basis of all cancers, potential targets for therapy and treatment protocols employed to improve the management of cancer patients. The journal also focuses on the impact of management programs and new therapeutic agents and protocols on

\section{Dovepress}

patient perspectives such as quality of life, adherence and satisfaction. The manuscript management system is completely online and includes a very quick and fair peer-review system, which is all easy to use. Visit http://www.dovepress.com/testimonials.php to read real quotes from published authors. 